\title{
SISTEM INFORMASI PERMINTAAN DAN PENGADAAN BARANG UNTUK INSTALASI VSAT DI PT.TELKOMSAT
}

\author{
Ramdani $^{1}$, Mei Lestari ${ }^{2}$, Ni Wayan Parwati ${ }^{3}$ \\ Program Studi Informatika, Fakultas Teknik dan Ilmu Komputer, Universitas Indraprasta PGRI \\ Jalan Raya Tengah No 80, Kelurahan Gedong, Pasar Rebo, Jakarta Timur \\ ramdani070516@gmail.com¹,mei_lestari@unindra.ac.id²,ni_wayanparwati@unindra.ac.id ${ }^{3}$
}

\begin{abstract}
Abstrak
Tujuan analisa perancangan sistem permintaan dan pengadaan barang ini adalah untuk mempermudah mengelola data permintaan dan pengadaan yang terdapat di PT. Telkomsat agar pekerjaan admin Service Delivery menjadi efektif dan efisien. Metode penelitian yang digunakan dalam sistem permintaan dan pengadaan barang di PT Telkomsat ini adalah metode kualitatif yaitu dengan mengamati langsung, wawancara dengan pihak terkait dan melakukan dokumentasi untuk mendapatkan informasi yang dibutuhkan. Peneliti juga melakukan penelitian dengan membandingkan melalui referensi buku dan media lain yang memuat informasi yang dibutuhkan, menganalisa kebutuhan, perancangan, implementasi, pengkodean, dan pengujian. Aplikasi Sistem Informasi ini membantu pengolahan data permintaan dan pengadaan barang yang terkomputerisasi dan terjaga keamanannya dalam mengolah data permintaan dan pengadaan untuk lebih cepat dalam hal pengerjaan pembuatan laporan dibanding dengan sistem yang berjalan saat ini.
\end{abstract}

Kata Kunci : Sistem Informasi,Pengadaan Barang, Java, komputerisasi

\begin{abstract}
The purpose of the design analysis of the demand and procurement system is to facilitate the management of the demand and procurement data contained in the PT. Telkomsat so that the Service Delivery admin work becomes effective and efficient. The method of research used in the system of demand and procurement of goods in PT Telkomsat is a qualitative method that is by observing directly, interviews with related parties and do documentation to get the information needed. Researchers are also conducting research by comparing through references to books and other media that contain the required information, analysing needs, designing, implementing, coding, and testing. This information system application helps the processing of data request and procurement of goods that are computerized and maintained in the processing of demand and procurement data for faster in terms of the creation of reports than with Current running system.
\end{abstract}

Keywords: Procurement Information System, Java, Computerized

\section{PENDAHULUAN}

Dengan berkembangnya teknologi, maka hal ini dapat mempermudah karyawan untuk membuat permintaan dan pengadaan barang serta mempermudah perusahaan untuk mengelola data secara real time (Sutabri, 2012). PT. Telkomsat adalah salah satu perusahaan yang bergerak di bidang penyediaaan layanan telekomunikasi berbasis satelit yang mana pada setiap bulan melakukan perhitungan rekapitulasi permintaan dan pengadaan barang yang masih dilakukan secara manual dalam artian pada suatu pendataan pembukuan masih tersimpan dalam kumpulan berkas, yang mungkin saja hal ini dapat menyebabkan adanya kekurangan dan kesalahan yang di lakukan oleh karyawan. Maka dari itu saat ini PT Telkomsat membutuhkan sistem informasi dengan database(Minarmi \& Susanti, 2014) yang aman. Agar kesalahan pada saat mencari dokumen untuk permintaan perangkat namun dokumen yang di cari tidak dapat di temukan. Berdasarkan uraian diatas maka peneliti tertarik untuk melakukan penelitian yang berjudul "Sistem Informasi Permintaan dan Pengadaan Barang untuk Instalasi Very Small Aparture Terminal di PT. Telkomsat Berbasis Java". 


\section{PENELITIAN RELEVAN}

Pada awal penelitian peneliti telah melakukan beberapa pengamatan mengenai aturan bisnis yg ada di PT Telkomsat terutama dalam proses permintaan dan pengadaan barang untuk instalasi, dimana saat proses permintaan berlangsung masih dilakukan secara manual sehingga dapat menyebabkan hilang nya berkas dan proses pencarian data yang lambat, sehingga dapat menghambat untuk proses selanjutnya. Dengan demikian ada beberapa penelitian yang menjadi acuan peneliti untuk membuat sistemn informasi tersebut antara yaitu :

Penelitian yang pertama diambil dari jurnal dengan judul Sistem Monitoring Menggunakan Mini PC dengan hasil penelitian Penggunaan dari Mini PC Raspberry Pi sebagai pengganti komputer adalah untuk mendapatkan biaya pembangunan sistem serta penggunaan biaya listrik yang lebih murah. Berdasarkan hasil pengujian yang dilakukan menunjukkan bahwa kinerja Raspberry Pi didapatkan penggunaan CPU mencapai 100\% dari kapasitas dan penggunaan RAM mencapai 32\% dari kapasitas yang tersedia. Walaupun dengan beban pemrosesan yang tinggi, Raspberry Pi tetap mampu menggantikan komputer dalam melakukan fungsi monitoring, sehingga tujuan pembangunan sistem serta penggunaan biaya listrik yang murah dapat tercapai.(Permana, 2014).

Penelitian yang kedua diambil dari jurnal dengan judul Analisis Dan Perancangan Sistem Informasi Manajemen Aset TIK Kesimpulan yang dapat ditarik adalah Perancangan Sistem Informasi Manajemen Aset Teknologi Informasi dan Komunikasi telah berhasil dilakukan dengan pendekatan berorientasi objek (OOA). Perancangan sistem dengan pendekatan berorientasi objek (OOA) dapat mendekatkan hubungan antara perangkat lunak yang dirancang dengan lingkungan penggunanya serta membantu dalam menentukan fungsionalitas sistem sesuai dengan kebutuhan penggunanya. Dengan fungsionalitas menghitung depresiasi aset, aset dapat diprediksi masa ekonomisnya, dan dengan adanya fungsionalitas pemindahan aset atau pengesetan status fisik aset, diperoleh masa layanan aset. Dari fungsionalitas-fungsionalitas ini aset dapat dihitung kebermanfaatannya bagi institusi dengan menghitung perbandingan masa layanan dengan masa ekonomis (Witama et al, 2019).

\section{METODE PENELITIAN}

Metode penelitian yang peneliti gunakan adalah metode Grounded Research yaitu metode penelitian berdasarkan pada fakta dan menggunakan analisis perbandingan dengan tujuan menetapkan konsep, membuktikan teori, mengembangkan teori, pengumpulan dan analisis data dalam waktu yang bersamaan.

Metode pengumpulan data yang dilakukan untuk mendapatkan data-data serta informasi untuk mendukung penyempurnaan hasil dari penelitian ini antara lain :

\section{Studi Pustaka}

Pengumpulan data dan informasi dari kutipan-kutipan, buku-buku, peraturan perundangundangan, serta hasil laporan dan bahan lainnya yang berkaitan dengan penelitian ini.(Supriyadi, 2017)

\section{Studi Lapangan}

\section{a. Wawancara}

Dimana diadakan tanya jawab kepada (Rosaliza, 2015) Admin Asset, logistik dan project PT. Telkomsat mengenai kondisi pengelolaan data permintaan dan pengadaan barang untuk instalasi VSAT yang digunakan sampai saat ini, mulai dari pengajuan permintaan, pengadaan barang untuk instalasi.

\section{b. Observasi}

Peneliti mempelajari dan mengamati sistem yang terdapat pada PT.Telkomsat serta keterkaitan antara subsistem satu dengan yang lainnya dengan meninjau tentang permintaan barang dan pengadaan jika ada permintaan instalasi baru. perusahaan tersebut, 
kemudian mengadakan pengamatan untuk memahami sistem berjalan terutama pada proses permintaan dan pengadaan barang untuk instalasi(Septianzah et al., 2019).

\section{HASIL DAN PEMBAHASAN}

Diagram Alir Data (DAD)

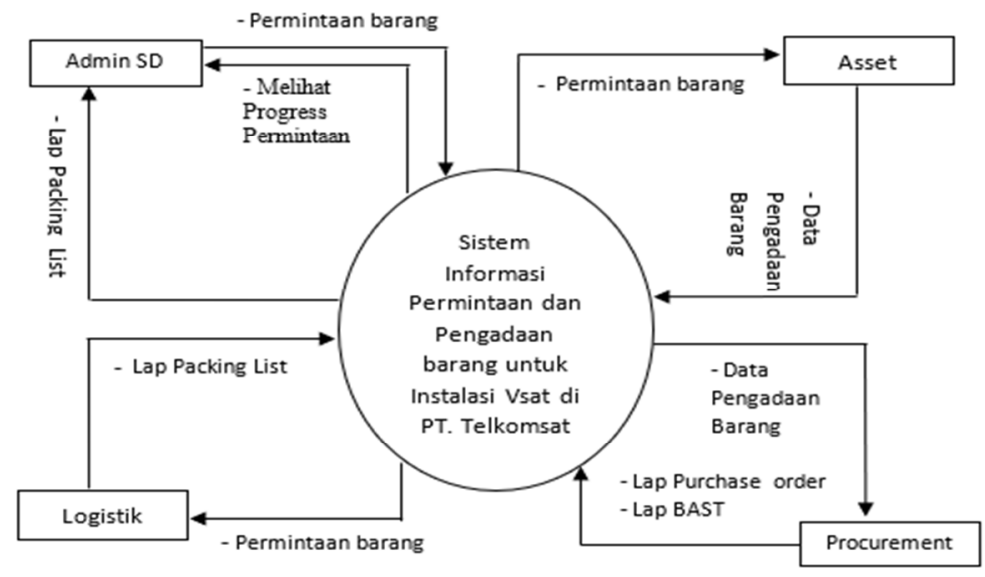

Gambar 1. Diagram Konteks

Gambar diatas merupakan diagram alir data yang menunjukan setiap proses dari awal permintaan barang samapai proses penyiapan barang yang akan dikirm ke lokasi tempat instalasi VSAT.

a. Permintaan Barang

Permintaan barang adalah permintaan yang dibuat oleh tim atau divisi service delivery (project) yang ditujukan kepada divisi logistik barang untuk dapat mengirimkan suatu barang yang sedang dibutuhkan oleh divisi project tersebut. Permintaan dalam hal ini yaitu berkaitan dengan projek instalasi perangkat sesuai dengan kebutuhan pelanggan untuk membuat suatu koneksi internet berbasis satelit. dimana permintaan itu berupa Antena Satelit, Modem, Feedhorn, BUC, LNB, Konektor, dan lain-lain.

Dalam permintaan barang tersebut membutuhkan surat. Surat ini disebut juga dengan surat permintaan barang. Surat permintaan barang ini adalah salah satu surat resmi dimana divisi project membutuhkan barang agar dapat dikirim barang dari divisi logistik sesuai dengan yang dibutuhkan untuk instalasi(Atikah, 2017).

b. Pengadaan

Menurut Peraturan Presiden Nomor 54 tahun 2014 Pengadaan Barang/Jasa adalah kegiatan untuk memperoleh Barang/Jasa oleh Kementerian/Lembaga/Satuan Kerja Perangkat Daerah/Institusi lainnya yang prosesnya dimulai dari perencanaan kebutuhan sampai diselesaikannya seluruh kegiatan untuk memperoleh Barang/Jasa.

Tujuan dengan adanya proses pengadaan barang adalah untuk memudahkan dan melancarkan kegiatan yang ada pada suatu perusahaan dalam memenuhi kebutuhan barang sebagai penunjang dalam setiap kegiatannya.(Veza, 2017).

Prosedur pengadaan barang untuk instalasi VSAT antara lain sebagai berikut:

1) Setelah menerima surat maka persiapan pengadaan barang

2) Barang dicek kembali dengan kondisi baik

3) Memberikan barang kepada divisi project

4) Membuat Laporan Packing List 


\section{Entity Relationship Diagram (ERD)}

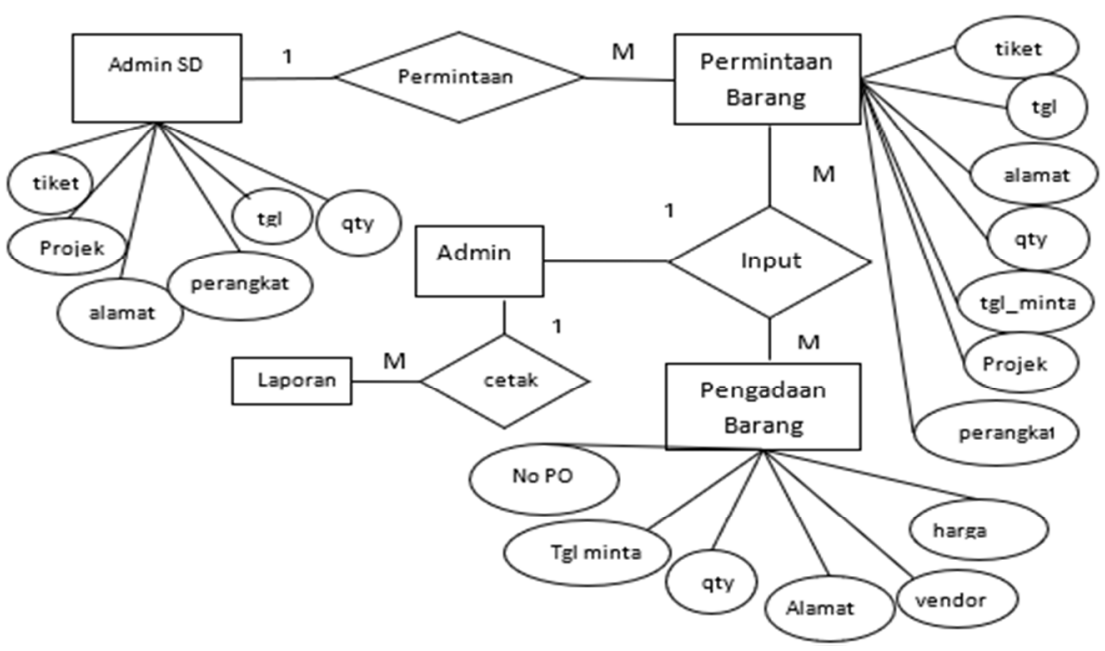

Gambar 2. Entity Relationship Diagram

Gambar diatas merupakan bentuk dari entity relationship diagram dari sebuah alur data yang akan mengalir dari satu proses ke proses berikut nya hingga menjadi sebuah data yang dapat digunakan untuk laporan permintaan dan pengadaan barang yang dibutuhkan oleh PT Telkomsat.

\section{Tampilan Aplikasi}

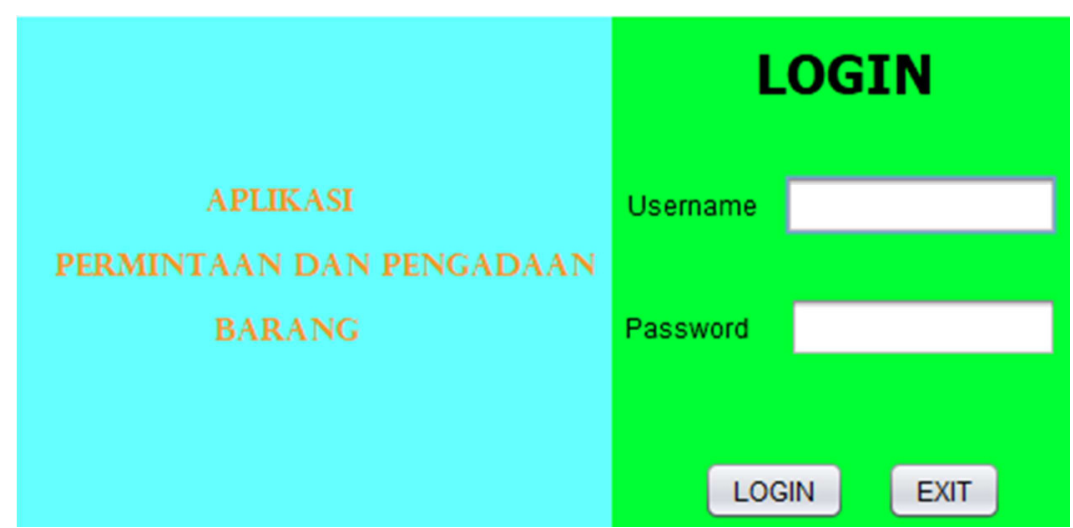

Gambar 2. Tampilan Form Login

Pada menu login ini menampilkan form untuk masuk kedalam aplikasi permintaan dan pengadaan barang. 


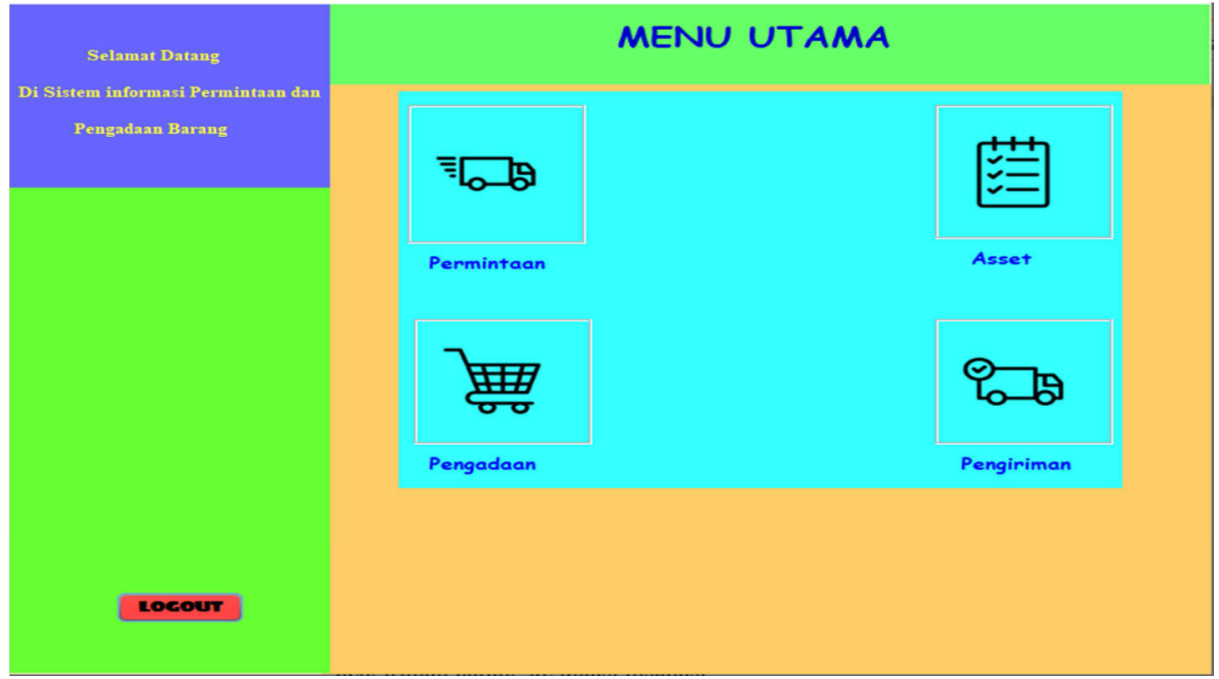

Gambar 3. Tampilan Form Menu Utama

Pada Tampilan menu utama ada bebrapa pilihan untuk masing-masing bagian yaitu form permintaan,pengadaan, asset dan pengiriman barang.

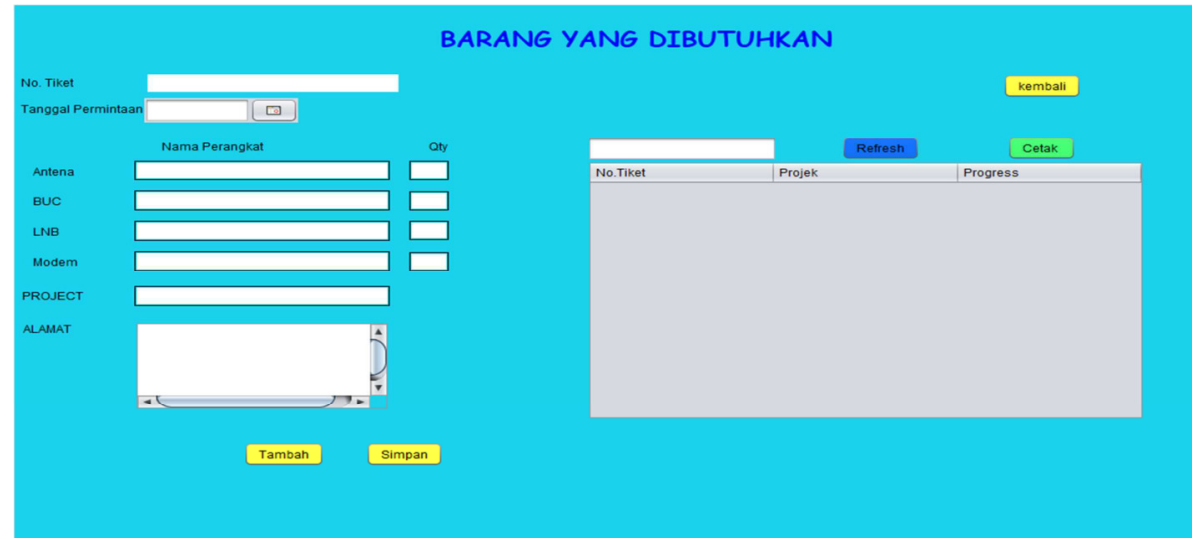

Gambar 4. Tampilan Form Permintaan Barang

Tampilan form Permintaan Barang yang di butuhkan untuk instalasi sesuai dengan lokasi yang tujuan pemasangan perangkat

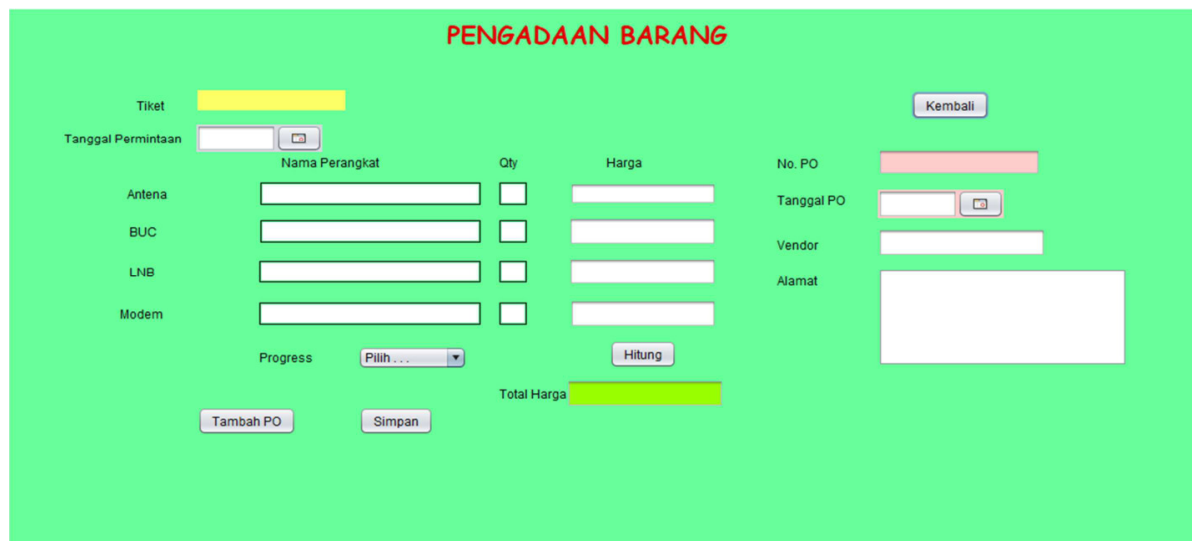

Gambar 5. Tampilan Form Pengadaan 
Tampilan form pengadaan barang yaitu berfungsi untuk pengadaan barang yang dibutuhkan untuk instalasi

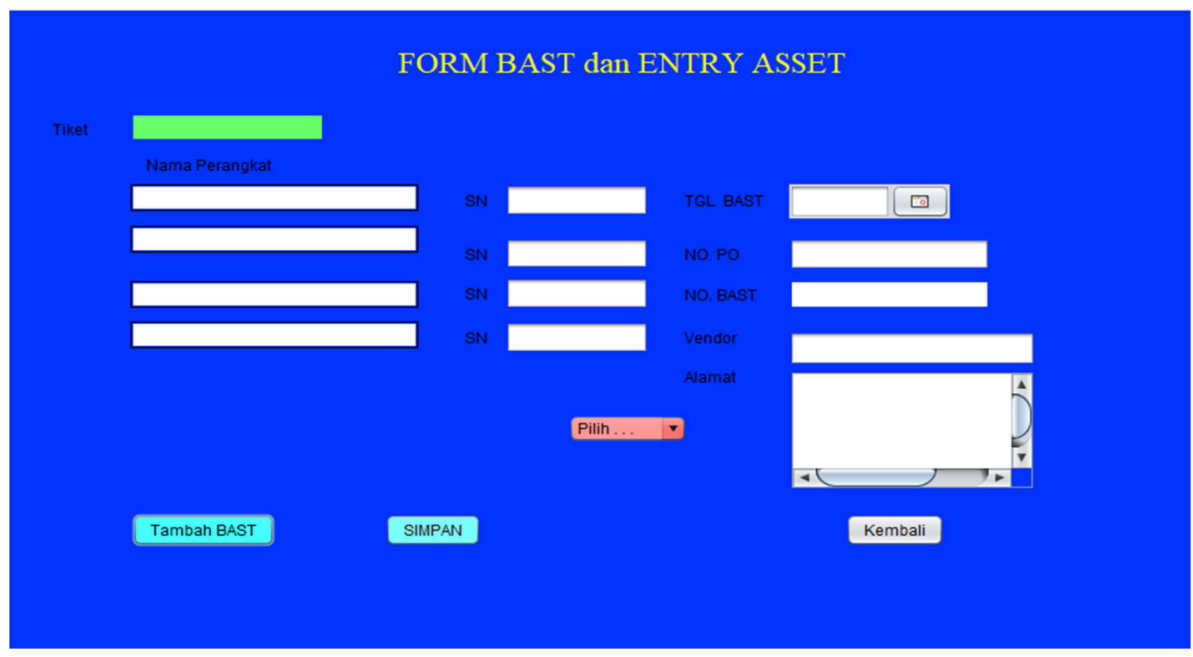

Gambar 6. Tampilan Form BAST dan Data Asset

Tampilan form BAST yaitu berfungsi untuk menginfokan barang yang sudah diterima dari vendor sebagai karen telah menerima barang yang dibeli.

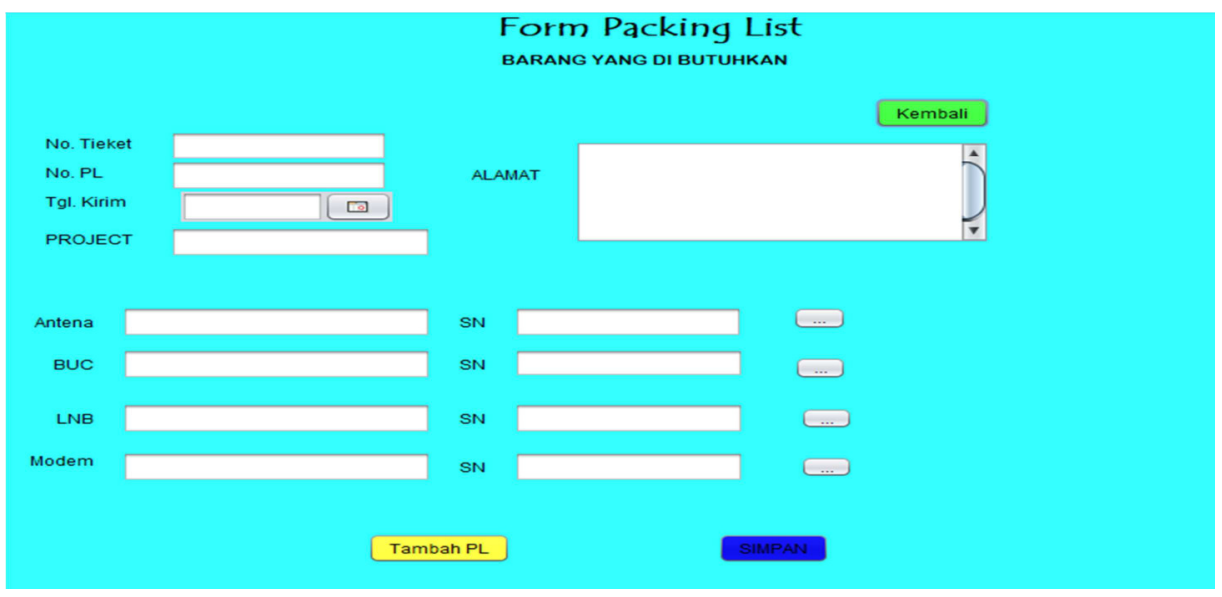

Gambar 7. Tampilan Form Packing List

Tempilan Form Packing List adalah untuk memberikan bukti bahwa barang yang di minta oleh bagian Service Delivery dan siap dikirim ke lokasi pemasangan perangkat 


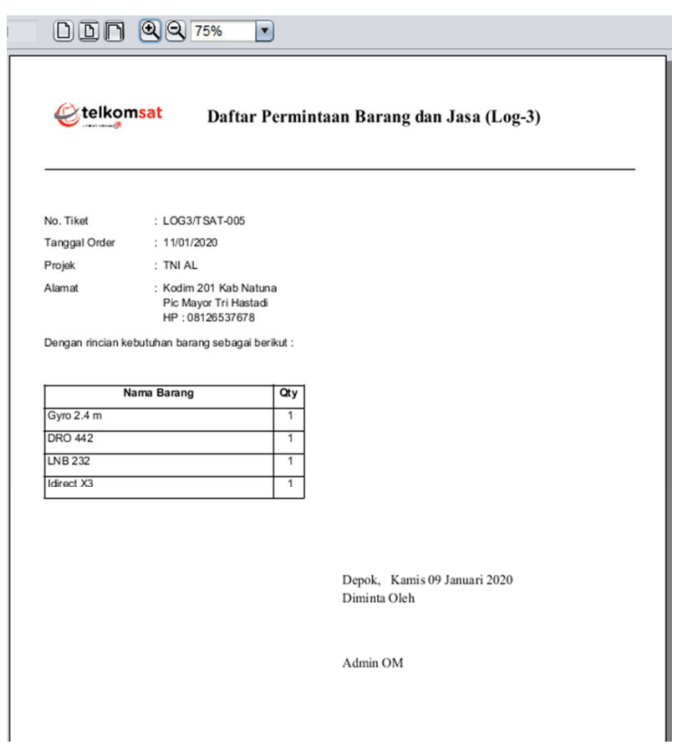

Gambar 8. Tampilan Laporan Permintaan Barang

Tampilan berikut merupakan layar keluaran data permintaan barang dari proses entry permintaan barang untuk instalasi.

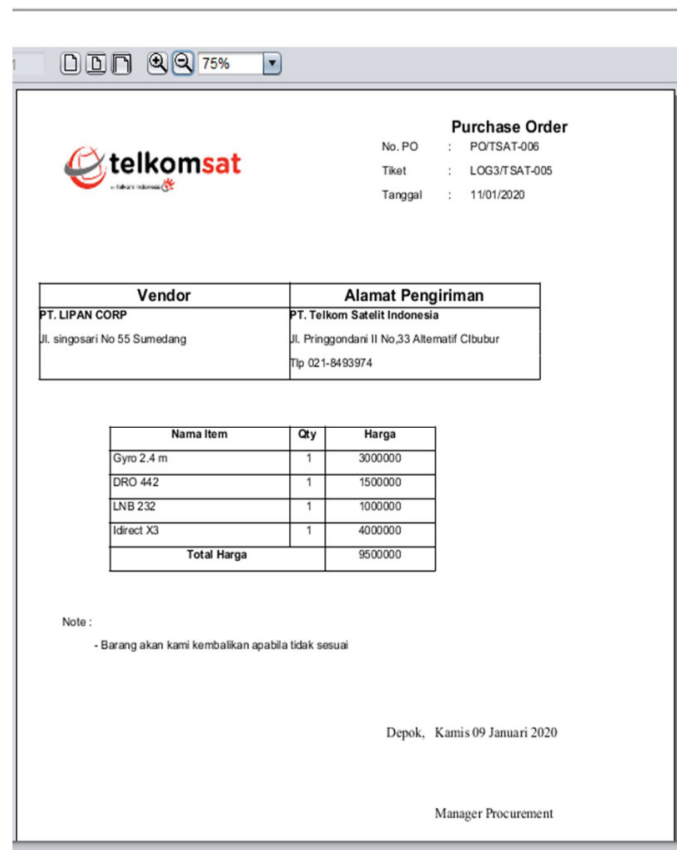

Gambar 9. Tampilan Laporan Purchase Order

Tampilan berikut merupakan layar keluaran data purcahse order dari proses entry data PO pembelian barang untuk instalasi.

Gambar 10. Tampilan Laporan BAST

Tampilan berikut merupakan layar keluaran data beriata acara serah terima dari proses entry data BAST dan Entry Asset barang yang telah diterima oleh PT.Telkomsat. 


\section{SIMPULAN}

Dengan dibuatnya Sistem Informasi Permintaan Dan Pengadaan Barang Untuk Instalasi Very Small Aparture Topology di PT.Telkomsat, semua kegiatan yang berhubungan dengan pengolahan data permintaan dan pengadaan barang tidak lagi menggunakan Microsoft Excel,(Iswandy, 2016) tetapi permintaan dan pengadaan barang menggunakan media berupa aplikasi yang tersistem. Dengan adanya sistem aplikasi sebagai alat bantu, peneliti dapat menyimpulkan bahwa dengan menggunakan sistem ini dapat memberikan beberapa keuntungan sebagai berikut:

1. Dengan menggunakan sistem aplikasi sistem informasi permintaan dan pengadaan untuk instalasi vsat di PT.Telkomsat akan mengalami peningkatan dalam menangani proses seluruh data dibandingkan dengan sistem yang berjalan saat ini.

2. Pengolahan data sistem permintaan lebih efektif, serta keamanan terhadap data lebih terjamin.

3. Proses dalam pembuatan laporan dapat dilakukan dengan cepat dan akurat.

4. Memudahkan administrator untuk memantau atau mengontrol data yang ada dalam database.

5. Pengawasan terhadap pelaksanaan kegiatan lebih mudah, karena adanya laporan atau informasi kegiatan yang tepat waktu dan dapat disajikan setiap saat bila dibutuhkan.

\section{DAFTAR PUSTAKA}

Atikah, A. (2017). Analisa dan Perancangan Sistem Informasi Pengadaan Bahan Baku Pada PT.XYZ. STRING (Satuan Tulisan Riset Dan Inovasi Teknologi), 1(2), 109. https://doi.org/10.30998/string.vli2.1030

Iswandy, E. (2016). Analisa Dan Perancangan Sistem Informasi Penagihan Purchasing Order Customer Studi Kasus Pada Cv. Vertical Cipta Relasi Padang Dengan Metode Centralized Data Processing. Jurnal TEKNOIF, 4(Oktober), 14.

Minarmi, \& Susanti. (2014). Jurnal Momentum ISSN : 1693-752X SISTEM INFORMASI INVENTORY OBAT PADA RUMAH SAKIT UMUM DAERAH ( RSUD ). Jurnal Momentum, 16(1), 103-111.

Permana, D. T. (2014). Sistem Monitoring Menggunakan Mini PC Raspberry Pi. Teknik Komputer Unikom - Komputika, $3(1), 1-6$.

Rosaliza, M. (2015). Wawancara, Sebuah Interaksi Komunikasi Dalam Penelitian Kualitatif. In Jurnal Ilmu Budaya (Vol. 11, Issue 2, pp. 71-79). https://doi.org/10.31849/jib.v11i2.1099

Septianzah, K., Informatika, P. S., \& Oriented, O. (2019). PEMBANGUNAN SISTEM INFORMASI MANAJEMEN INVENTORY PADA PT TOTAL BANGUN PERSADA DENGAN MENGGUNAKAN TEKNOLOGI WEBBASE. 3(3), 239-246.

Supriyadi, S. (2017). Community of Practitioners: Solusi Alternatif Berbagi Pengetahuan antar Pustakawan. Lentera Pustaka: Jurnal Kajian Ilmu Perpustakaan, Informasi Dan Kearsipan, 2(2), 83. https://doi.org/10.14710/lenpust.v2i2.13476

Sutabri, T. (2012). Analisis Sistem Informasi. In Analisa Sistem Informasi.

Veza, O. (2017). PERANCANGAN SISTEM INFORMASI INVENTORY DATA BARANG PADA PT.ANDALAS BERLIAN MOTORS (Studi Kasus : PT Andalas Berlian Motors Bukit Tinggi). Jurnal Teknik Ibnu Sina (JT-IBSI), 2(2), 121-134. https://doi.org/10.36352/jt-ibsi.v2i2.63

Witama, M. N., Informatika, P. S., \& Barang, P. A. (2019). Perancangan Aplikasi Pengelolaan Aset Barang. 3(3). 